\title{
SEAKEEPING PERFORMANCE OF A HYDROFOIL IN WAVES USING CFD APPROACH
}

\author{
SYAFIQ ZIKRY AND FITRIADHY*
}

Faculty of Ocean Engineering Technology and Informatics, Universiti Malaysia Terengganu, 21030 Kuala Terengganu, Terengganu, Malaysia

${ }^{*}$ Corresponding author: naoe.afit@gmail.com

http://doi.org/10.46754/umtjur.2021.07.017

\begin{abstract}
Hydrofoil usually experiences high resistance and excessive vertical motions (heave and pitch) that may affect the passenger's comfort due to the harsh environmental condition. Therefore, it is necessary to investigate seakeeping performance of a hydrofoil ship in waves due to the presence of a complex hydrodynamic phenomenon. To achieve this objective, an analysis of Computational Fluid Dynamic (CFD) approach on a hydrofoil ship motion is proposed. Several parameters such as Froude Number and foil angle of attack have been taken into account. The results revealed that the subsequent increase of Froude Number was inversely proportional to the heave and pitch motions. Inherently, these have led to an upgrade of hydrofoil seakeeping performances presented in the form of high Response Amplitude Operators (RAO). Furthermore, the increasing angle of the foil bow was proportional to the heave motion while for the foil stern, $7.5^{\circ}$ showed lower heave motion, then followed by $5^{\circ}$ and $10^{\circ}$ respectively. For the pitch motion, the increase of foil bow was lower at $5^{\circ}$ then followed by $10^{\circ}$ and $7.5^{\circ}$. The increase of the foil stern was proportional to the pitch motion experiences by a hydrofoil. In general, this CFD simulation is very beneficial to ensure operational effectiveness of hydrofoil design in high sea states with respect to the aforementioned design parameter.
\end{abstract}

Keywords: CFD, hydrofoil, foil angle of attack, heave, pitch.

\section{Introduction}

As development in the marine transportation, a hydrofoil craft is designed due to an increasing demand on high-speed craft. The hydrofoil structure installed under the hull has developed enough lift to push the ship out of the water. This greatly reduces the draft of the ship as well as its wetted surface area as it increases the speed of the ship (Djavareshkian \& Esmaeili, 2014). According to Matveev and Duncan (2005), hydrofoils have reduced fuel consumption on small vessels by almost half and considerably improved seaworthiness. As a normal vessel, the performance of a hydrofoil ship is a very prominent aspect to be analyzed in the early design stage to keep the ship comfortable, effective, and safe to use.

Several researchers had studied on the ship seakeeping behaviour using experimental approaches. Vakilabadi, Khedmati, and Seif (2014), Islam, Jahra, and Hiscock (2016) and Sun, Yao, Xiong, and Ye (2017) have experimentally conducted model test at towing tank. Even so, the experimental method is a time-consuming, complex process and costly (Fitriadhy \& Adam, 2017). Therefore, another alternative to predict the seakeeping behavior of hydrofoil ship is via numerical method.

This paper presents Computational Fluid Dynamics (CFD) analysis on heave and pitch motions of a hydrofoil ship. Several parameters such as various foil angle of attack and Froude numbers have been considered. A commercial CFD software, namely Flow3D, was utilized by applying the incompressible unsteady Reynolds-Averaged Navier Stokes equations in which RANSE and continuity equations are discretized by the finite volume method based 
on Volume of Fluid (VOF) to deal with the non-linear free surface. In addition, the mesh generation, boundary condition, initial condition and numerical option were carefully determined before simulations. Basically, this simulation solved the mesh independent study to select the optimal domain discretization. The Response Amplitude Operator (RAO) of heave and pitch motion performances was then discussed.

\section{Theoretical Background}

\section{Heave and pitch motion}

The degree of freedom (D.O.F) represented the possible translations and rotation of the body. The heave and pitch motion noted as translation and rotation respectively along $\mathrm{X}, \mathrm{Y}$ and $\mathrm{Z}$ axis define the behavior of the hydrofoil ship during sailing. Heave motion is the linear vertical upward and downward acceleration of ships along their vertical axis. Only in an absolute calm are upward and downward motions at equilibrium and the ship floats at rest and pitch motion is lifted at the bow and lowered at the stern and vice versa. The equations are demonstrated as Equation 1 and 2 (Fitriadhy \& Adam, 2017):

$\left(M+A_{33}\right) \frac{d^{2} \eta_{3}}{d t_{2}}+B_{33} \frac{d \eta_{3}}{d t}+C_{33} \eta_{3}+A_{35} \frac{d^{2} \eta_{5}}{d t_{2}}+B_{35} \frac{d \eta_{5}}{d t}+C_{35} \eta_{5=} F_{3}$

$A_{53} \frac{d^{2} \eta_{3}}{d t_{2}}+B_{53} \frac{d \eta_{3}}{d t}+C_{53} \eta_{3}+\left(I_{55}+A_{35}\right) \frac{d^{2} \eta_{5}}{d t_{2}}+B_{35} \frac{d \eta_{5}}{d t}+C_{55} \eta_{=} F_{5}$

In these equations, $\mathrm{M}$ is the vessel mass, $I_{55}$ is the moment of inertia in pitch and $A_{i h}, B_{i j}$, and $\mathrm{C}_{\mathrm{ij}}$ are coefficients of added mass, damping and restoring coefficient, respectively. Also, $\mathrm{F}_{3}$ and $\mathrm{F}_{5}$ are vertical force and longitudinal subverting moment on the vessel respectively (Seif, Mehdigholi, \& Najafi, 2014).

\section{Wave}

A conceptual model to describe the elevation of an irregular sea is given by the sum of a large number of essentially independent regular (sinusoidal) contributions with random phases. In this representation, the sea elevation at a location $\mathrm{x}, \mathrm{y}$ with respect to an inertial reference frame is given by Equation 3:

$\zeta(x, y, t)=\sum_{i=0}^{N} \zeta_{i}(x, y, t)=\sum_{i=0}^{N} \zeta_{i} \cos (k i x \cos \chi+k i y \sin \chi+\omega i t+\theta i)$

where $\zeta \mathrm{i}(\mathrm{x}, \mathrm{y}, \mathrm{t})$ is the contribution of the regular or harmonic travelling wave components i progressing at an angle $\chi$ with respect to the inertial frame and a with random phase $\theta i$. The parameters ki (wave number), $\omega$ i (wave frequency seen from a fixed position), $\zeta \mathrm{i}$ (constant wave amplitude) characterize each component. For each realization, the phase $\theta \mathrm{i}$ of each component is chosen to be a random variable with uniform distribution on the interval $[-\pi, \pi]$. This choice ensures the stationarity of $\zeta(x, y, t)$ (Manual, 2011). For each regular wave component $i$, the phase velocity, ci, is the velocity with which the wave crest moves relative to ground. Assuming infinite depth of water is presented in Equation (4):

$$
c_{i}=\sqrt{\frac{g \lambda i}{2 \pi}} ; \quad k_{i}=\sqrt{\frac{2 \pi}{\lambda i}} ; \quad w_{i}=\sqrt{g} k_{i}=\frac{g}{c_{i}} ;
$$

where $\lambda i$ is the wavelength of the component i. The last expression is known as the dispersion of gravity waves and establishes that the phase velocity is inversely proportional to its frequency. This means that long waves propagate faster than short ones. This phenomenon is important for simulating ship motion in waves as we shall see in the following sections of the report: a ship advancing in a seaway in following seas will overtake some short waves, while it will be overtaken by some long ones (Manual, 2011).

\section{Turbulence Model}

In the current CFD simulation, Renormalization-group (RNG) turbulence model has been selected, taken into consideration low Reynolds number effects (Koutsourakis, Bartzis, \& Markatos, 2012; A. Yakhot, Rakib, \& Flannery, 1994; V. Yakhot \& Orszag, 1986). Application of the double averaging strategy to the transport equations for Turbulent Kinetic Energy (TKE) 
and its dissipation rate produces the turbulence model for the flow as displayed in Equations (5)-(8).

$$
\begin{aligned}
& \frac{\delta \mathrm{k}}{\delta \mathrm{t}}+\mathrm{U}_{\mathrm{j}} \frac{\delta \mathrm{k}}{\delta \mathrm{x}_{\mathrm{j}}}=\frac{\delta}{\delta \mathrm{x}_{\mathrm{j}}}\left[\left(\mathrm{v}+\frac{\mathrm{v}_{\mathrm{t}}}{\sigma_{\mathrm{k}}}\right) \frac{\delta \mathrm{k}}{\delta \mathrm{x}_{\mathrm{j}}}\right]+\mathrm{P}_{\mathrm{k}}+\mathrm{B}_{\mathrm{k}}+\mathrm{W}_{\mathrm{k}} \\
& \frac{\delta \varepsilon}{\delta \mathrm{t}}+\mathrm{U}_{\mathrm{i}} \frac{\delta \varepsilon}{\delta \mathrm{x}_{\mathrm{j}}}=\frac{\delta}{\delta \mathrm{x}_{\mathrm{j}}}\left[\left(\mathrm{v}+\frac{\mathrm{v}_{\mathrm{t}}}{\sigma_{\varepsilon}}\right) \frac{\delta \varepsilon}{\delta \mathrm{x}_{\mathrm{j}}}\right]+\mathrm{C}_{1 \varepsilon} \frac{\varepsilon}{\mathrm{k}}\left(\mathrm{P}_{\mathrm{k}}+\mathrm{B}_{\mathrm{k}}\right)\left(1+\mathrm{C}_{3 \varepsilon} \mathrm{R}_{\mathrm{f}}\right)+\mathrm{W}_{\varepsilon}-\mathrm{C} \\
& \mathrm{P}_{\mathrm{k}}=\mathrm{v}_{\mathrm{t}} \mathrm{S}^{2}=\mathrm{v}_{\mathrm{t}}\left(\frac{\delta \mathrm{U}_{\mathrm{i}}}{\delta \mathrm{x}_{\mathrm{j}}}+\frac{\delta \mathrm{U}_{\mathrm{j}}}{\delta \mathrm{x}_{\mathrm{i}}}\right) \frac{\delta \mathrm{U}_{\mathrm{i}}}{\delta \mathrm{x}_{\mathrm{j}}} \\
& \mathrm{B}_{\mathrm{k}}=\beta \mathrm{g}_{\mathrm{i}} \frac{\mathrm{v}_{\mathrm{t}}}{\sigma_{\mathrm{s}}} \frac{\delta s}{\delta \mathrm{x}_{\mathrm{i}}}
\end{aligned}
$$

where $\mathrm{P}_{\mathrm{k}}$ is the shear production term of TKE, $S=\sqrt{2 S_{i j} S_{i j}}$ is the average of strain tensor and $S_{i j}=\frac{1}{2}\left(\frac{\delta U_{i}}{\delta x_{i}}+\frac{\delta U_{j}}{\delta x_{i}}\right), B_{k}$ and $W_{k}$ are the buoyant and wake production terms of TKE, respectively. In addition, $W_{\varepsilon}$ is the wake production term in $\varepsilon, \sigma_{k}$ and $\sigma_{\varepsilon}$ are the turbulent Prandtl numbers for $k$ and $\varepsilon$, and $C_{i \varepsilon}, C_{3 \varepsilon}$ and $C^{*}{ }_{2 \varepsilon}$ are model coefficients.

\section{Simulation Conditions}

\section{Principle Data of Hydrofoil Ship}

The details of the hydrofoil ship are summarized in Table 1 .
Table 1: Dimension of the hydrofoil ship in full scale and model scale

\begin{tabular}{lll}
\hline Geometrical parameters & Full scale & Model scale \\
\hline $\begin{array}{l}\text { Length Overall, LOA } \\
(\mathrm{m})\end{array}$ & 32.64 & 16.32 \\
$\begin{array}{l}\text { Length Between } \\
\text { Perpendicular, LBP (m) }\end{array}$ & 32.276 & 16.138 \\
Beam, B (m) & 8.278 & 4.139 \\
Draft, T (m) & 1.4 & 0.7 \\
Ratio & $1: 2$ & \\
\hline
\end{tabular}

\section{Simulation parameter}

Several parametric studies such as various Froude numbers (Fr), foil's angle of attack indicate the Foil of stern (FS) and Foil of Bow (FB), as well as the wavelength ( have been taken into consideration. The details of simulation parameter are summarized in Table 2 and 3.

Table 2: Matrix of simulation with different Froude numbers and foil angle of attacks

\begin{tabular}{cccccccccc}
\hline \multirow{2}{*}{$\begin{array}{c}\text { Froude } \\
\text { Number }\end{array}$} & \multicolumn{9}{c}{ Angle of Attack } \\
\cline { 2 - 9 } & FS 5 & FS 7.5 & FS 10 & FS 5 & FS 7.5 & FS 10 & FS 5 & FS 7.5 & FS 10 \\
\hline 1.382 & - & $\sqrt{c}$ & - & - & - & - & - & - & - \\
1.423 & - & $\sqrt{7}$ & - & - & - & - & - & - & - \\
1.545 & - & $\sqrt{ }$ & - & - & - & - & - & - & - \\
1.626 & $\sqrt{ }$ & $\sqrt{ }$ & $\sqrt{ }$ & $\sqrt{ }$ & $\sqrt{ }$ & $\sqrt{ }$ & $\sqrt{ }$ & $\sqrt{ }$ & $\sqrt{ }$ \\
1.708 & - & $\sqrt{ }$ & - & - & - & - & - & - & - \\
1.830 & - & $\sqrt{ }$ & - & - & - & - & - & - & - \\
\hline
\end{tabular}

Table 3: Matrix of simulation with different wavelengths

\begin{tabular}{cccccccccc}
\hline Froude & \multicolumn{1}{c}{ Wavelength, $\lambda / \mathrm{Lpp}$} & Angle of Attack \\
\cline { 2 - 8 } Number & 0.50 & 0.75 & 1.00 & 1.25 & 1.50 & 1.75 & 2.00 & \\
\hline 1.626 & $\sqrt{ }$ & $\sqrt{ }$ & $\sqrt{ }$ & $\sqrt{ }$ & $\sqrt{ }$ & $\sqrt{ }$ & $\sqrt{ }$ & FB 5 FS 7.5 \\
\hline
\end{tabular}




\section{Computational Domain and Boundary Conditions}

In Flow 3D software, the computational domain is presented as structured mesh that is defined in a Cartesian. The global mesh (main mesh block) was set up with cell size of 0.144 , that means each cell was $14.4 \mathrm{~cm}$ of breadth, width, and depth. Local block (small mesh block), was set up, with cell size 0.072 which synchronized with the total number of cells as shown in
Figure 1. The total cells can be defined by a user or automatically calculated by Flow 3D. In this case, the nested block meshing solely depends on the ratios, which means the ratio of global cell size shall complement the local nested block size. It is important to prevent grid line intersection of overlapping with others, thus, reducing the complexity in computational simulation. In this research, the ratio of 1:2 was chosen due to time and accuracy considerations.
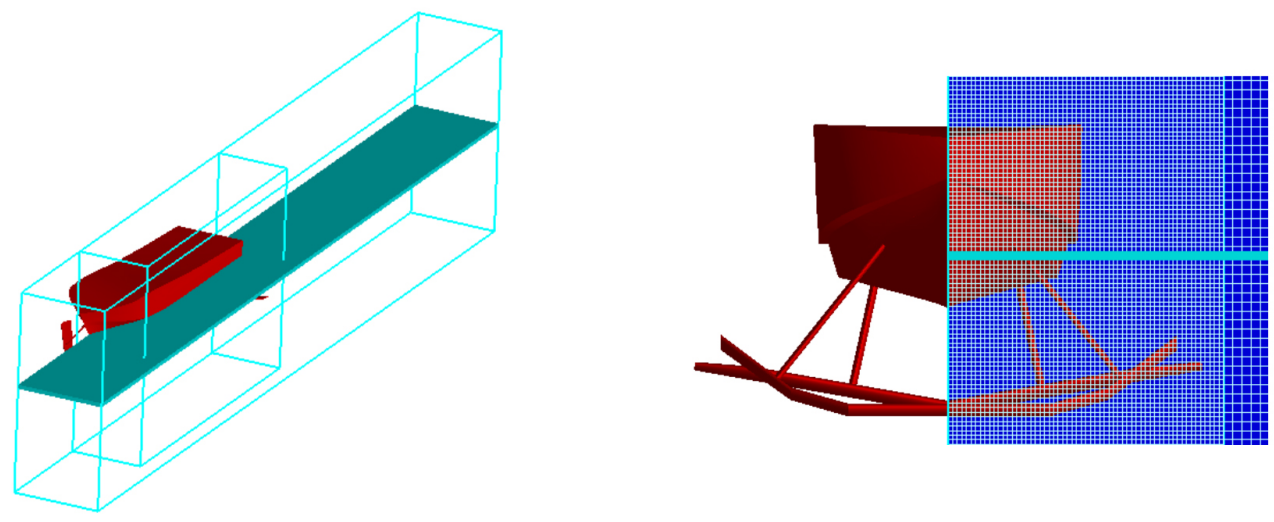

Figure 1: Overall mesh block being used in simulation

Table 4: Boundary condition settings

Location
X-min
X-max
Y-min
Y-max
Z-min
Z-max

Nested Block (All)
Type of boundary

Wave, Wv

Specified pressure, $\mathrm{P}$

Specified pressure, $\mathrm{P}$

Symmetry, $\mathrm{S}$

Symmetry, S

Specified pressure, $\mathrm{P}$

Symmetry, S
Remarks

Stimulate wave

Stimulate downstream

Stimulate pressure across boundary

Ship geometry is symmetry

No flux across boundary

Stimulate pressure across the boundary

has been chosen regardless of their performance on steadiness and computational time. The increase of total number of cells meshing up to $3,536,935$ was obviously unnecessary due to insignificant difference. 
Table 5: The mesh independent study on hydrofoil ship simulation

\begin{tabular}{cccc}
\hline Case & Total cell number & Time taken (hours) & Heave motion $(\mathrm{m})$ \\
\hline A & $1,895,733$ & 50 & 0.2867 \\
B & $2,246,994$ & 62 & 0.2265 \\
C & $2,929,615$ & 78 & 0.1692 \\
D & $3,536,935$ & 96 & 0.1281 \\
\hline
\end{tabular}
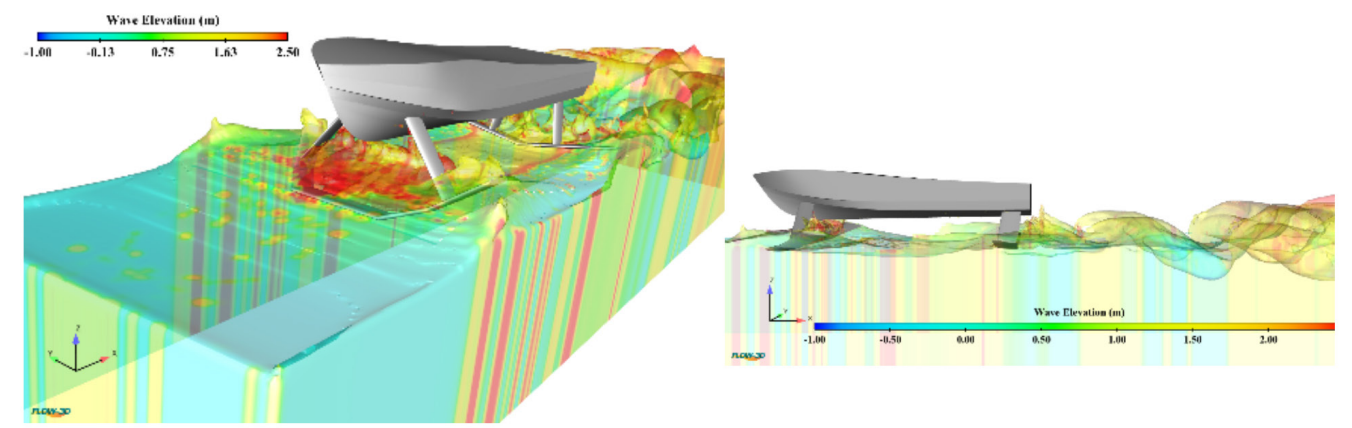

Figure 2: 3D (left) and 2D (right) views of wave elevation using case $\mathrm{C}$

\section{Results and Discussion}

The computational of fluid dynamic simulations has been carried out to predict the heaving and pitching motion of a hydrofoil due to effects of Froude number, different foil angles of attack and various wavelengths.

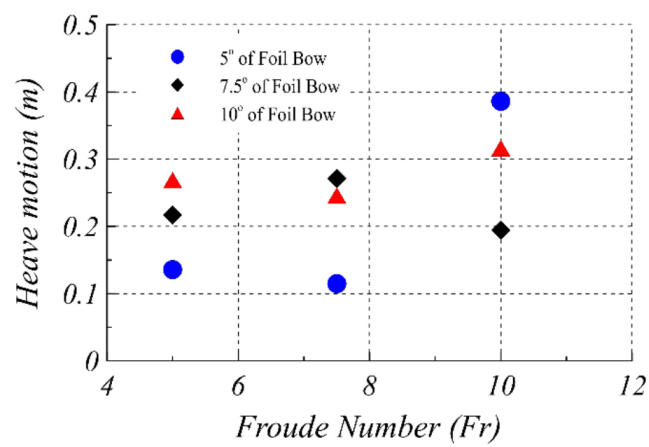

\section{Effect of Foil Angle of Attack on Hydrofoil}

The heave and pitch motions that were analyzed correlate with the lifting forces generated by the hydrofoil as shown in Figure 3.

Figure 3: Heave (left) and pitch (right) magnitude of various foil angles of attack on hydrofoil

The heave motion experienced by the hydrofoil at the various angles of the foil stern with constant angle of the foil bow are presented in Figure 3. In the case of a 5-degree angle of

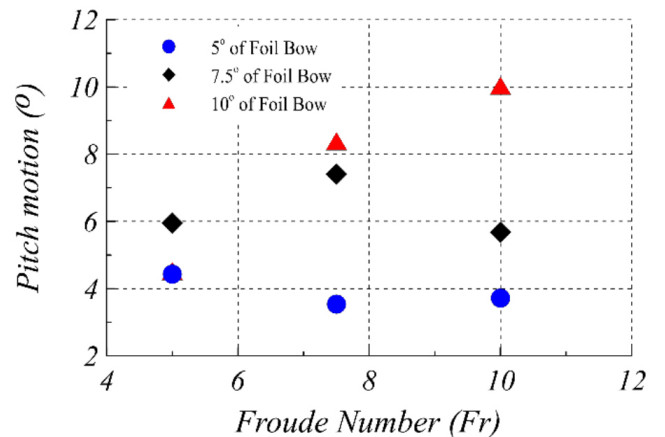

the foil bow, the lifting forces decrease at the foil stern at $7.5^{\circ}$ and then rise to a peak point at the foil bow at $10^{\circ}$. The same trend is shown by the foil bow with a 10-degree angle. However, with 
the foil bow of $7.5^{\circ}$, the lifting forces increase at the foil stern at $7.5^{\circ}$ before it declines at the foil stern at $10^{\circ}$. The graph reveals the pitch motion experiences by the hydrofoil at various angles of foil stern with constant angle of foil bow. For the foil bow of $5^{\circ}$, the pitch motion decreases from the foil stern of $5^{\circ}$ to the foil stern of $7.5^{\circ}$ and then slightly increases at the foil stern of $10^{\circ}$. Meanwhile, for the foil bow of $7.5^{\circ}$, the pitch motion increases from the foil stern of $5^{\circ}$ to $7.5^{\circ}$ before it decreases at the foil stern of $10^{\circ}$. For the foil bow of $10^{\circ}$ the pitch motion was perpendicular to the angle of the foil stern. Details of the results and the visualization are presented in Table 6 and Figure 4, respectively.

Table 6: Heave and pitch magnitude for various angles of attack

\begin{tabular}{cccc}
\hline \multicolumn{2}{c}{ Angle of Attack $\left({ }^{\circ}\right)$} & Heave Motion $(\mathrm{m})$ & Pitch Motion $(\circ)$ \\
\hline Bow & Stern & & 4.43 \\
5 & 5 & 0.1357 & 3.54 \\
& 7.5 & 0.386 & 3.72 \\
& 10 & 0.217 & 5.95 \\
7.5 & 5 & 0.2712 & 7.41 \\
& 7.5 & 0.1944 & 5.68 \\
& 10 & 0.2684 & 4.52 \\
& 5 & 0.2458 & 8.38 \\
& 7.5 & 0.3162 & 10.03 \\
\hline
\end{tabular}

a) $\mathrm{FB} 5^{\circ} \mathrm{FS} 5^{\circ}$

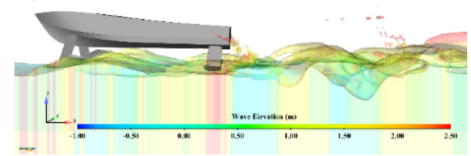

d) FB $7.5^{\circ} \mathrm{FS} 7.5^{\circ}$ b) $\mathrm{FB} 5^{\circ} \mathrm{FS}$

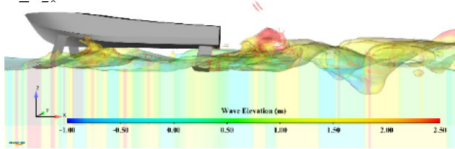

e) $\mathrm{FB} 10^{\circ} \mathrm{FS} 5^{\circ}$ c) FB $7.5^{\circ} \mathrm{FS}$

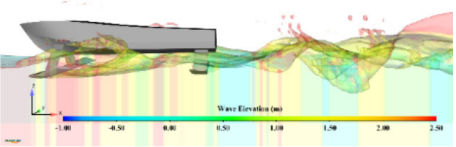

f) $\mathrm{FB} 10^{\circ} \mathrm{FS} 7.5^{\circ}$
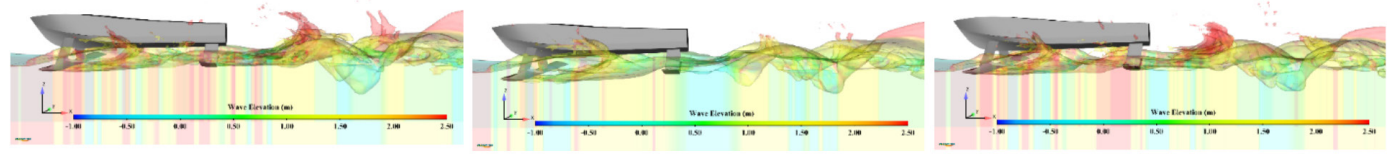

Figure 4: 2D view of wave elevation for various angles of attack

Effect of Various Froude Number (Fr) on Hydrofoil

For comparison purposes, the heaving and pitching motion for hydrofoil was tested on various Froude Numbers in the range of 1.382 until 1.83. The results are presented in Figure 5. The increase of heave motions is shown for $\mathrm{Fr}=$ 1.423 to $\mathrm{Fr}=1.83$ compared to the Fr between 1.382 and 1.423 .

The result analysis was reasonable for hydrofoil configurations that require enough speed to generate lifting forces and eventually, decreasing the drag force reaction between the hull and water surfaces. In this condition, the support hydrodynamics configurations enable the hydrofoil to maintain an even keel and stable hull run with high positive dynamics pressure. However, pitch motions show an opposite trend, subsequent increase from $\mathrm{Fr}=1.423$ to $\mathrm{Fr}=$ 1.626 was lower than pitch motion of $\mathrm{Fr}=1.626$ to $\mathrm{Fr}=1.83$. Details of data and visualization are shown as in Table 7. 

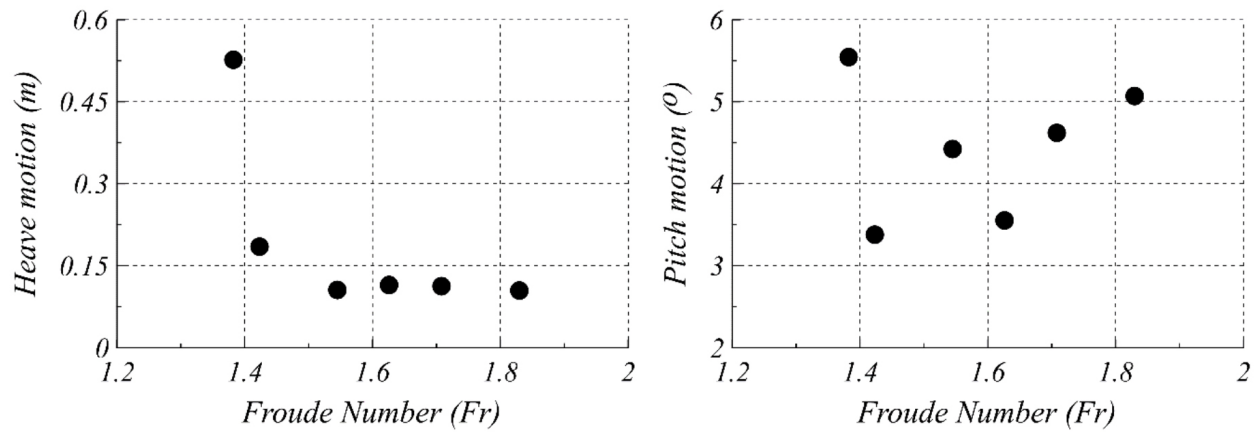

Figure 5: Heave (left) and pitch (right) magnitude of various Froude numbers

Table 7: Heave and pitch magnitude for Froude number

\begin{tabular}{ccc}
\hline Froude Number & Heave Motion $(\mathrm{m})$ & Pitch Motion $\left({ }^{\circ}\right)$ \\
\hline 1.382 & 0.5268 & 5.5463 \\
1.423 & 0.1851 & 3.3816 \\
1.545 & 0.1060 & 4.4231 \\
1.626 & 0.1147 & 3.5523 \\
1.708 & 0.1129 & 4.6204 \\
1.83 & 0.1048 & 5.0699 \\
\hline
\end{tabular}

a) $\mathrm{Fr}=1.423$

b) $\mathrm{Fr}=1.545$

c) $\mathrm{Fr}=1.626$

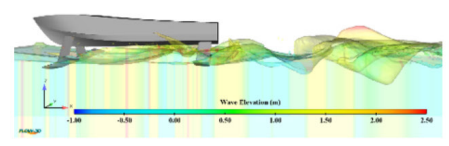

d) $\mathrm{F}=1.708$

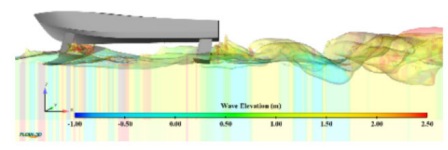

Figure 6: 2D view of wave elevation for various Froude numbers

\section{Effect of Wavelength}

In this case, hydrofoil was simulated in 7 different of $\lambda / \mathrm{Lpp}$. The effect of heaving and pitching motion was analyzed to investigate the seakeeping performance. The wave height was set as constant variable at $1.0 \mathrm{~m}$. The increase of $\lambda / \operatorname{Lpp} 0.5$ to 1.25 was proportional to the heave motion on hydrofoil and then, it slightly dropped at $\lambda /$ Lpp 1.5 about $-0.01 \%$ before it surged to the critical point at $\lambda / \operatorname{Lpp} 1.75$ and finally curved down at $\lambda /$ Lpp 2 as shown in Figure 7 . The hydrofoil experiences lowered seakeeping. 

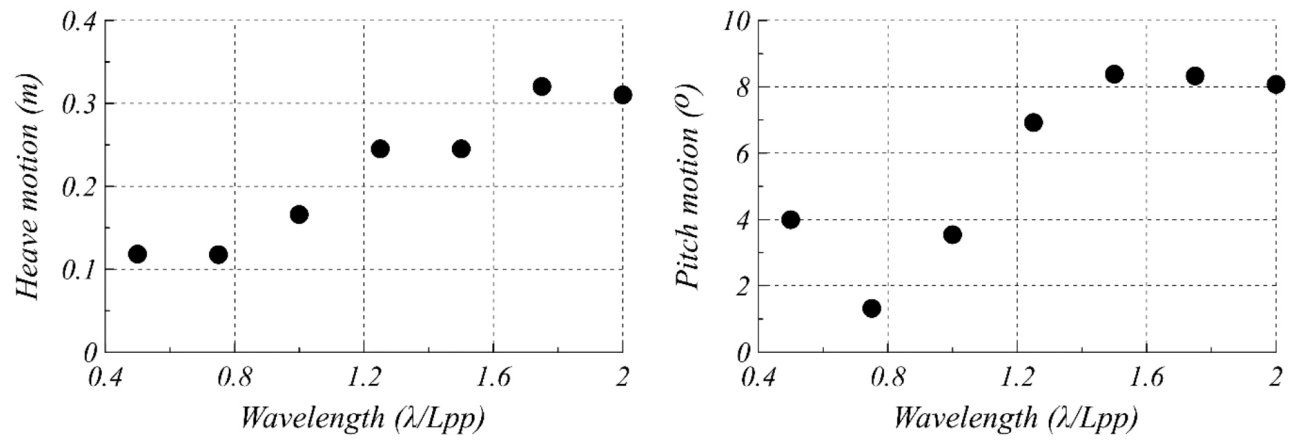

Figure 7: Heave (left) and pitch (right) magnitude of various wavelengths $(\lambda / \mathrm{Lpp})$

Table 8 Heave and pitch magnitude for various wavelengths

\begin{tabular}{ccc}
\hline Wavelength, $\lambda /$ Lpp & Heave Motion $(\mathrm{m})$ & Pitch Motion $\left({ }^{\circ}\right)$ \\
\hline 0.50 & 0.1183 & 3.992 \\
0.75 & 0.1176 & 1.322 \\
1.00 & 0.1661 & 3.537 \\
1.25 & 0.2451 & 6.917 \\
1.50 & 0.2451 & 8.385 \\
1.75 & 0.3203 & 8.325 \\
2.00 & 0.3102 & 8.078 \\
\hline
\end{tabular}

Based on Figure 7, the graph indicates that an increase of $\lambda / \operatorname{Lpp} 0.5$ to 0.75 was inversely proportional to the pitch motion. Then, the graph depicts maximum surge at $\lambda / \mathrm{Lpp} 0.75$ to $\lambda / \mathrm{Lpp}$ 1.5 before it declines to $\lambda / \operatorname{Lpp} 1.75$ and 2 . The peak point at $\lambda / \mathrm{Lpp} 1.5$ shows that the hydrofoil experiences more than 80 which is not compatible for seaworthiness. This condition is very dangerous for passengers and may cause accidents and structural damage as shown in Figure 8. The details of data are presented in Table 8 .

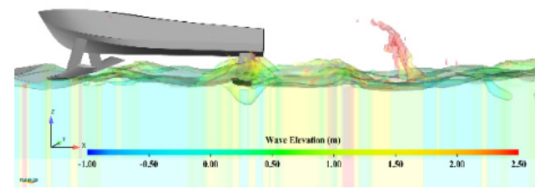

c) $\lambda / \mathrm{Lpp}=1.00$

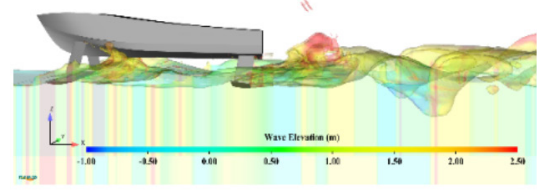

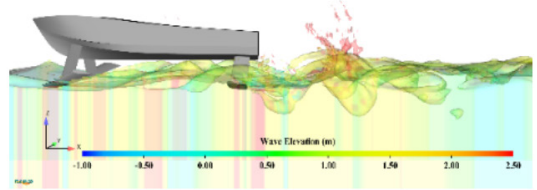

d) $\lambda / \operatorname{Lpp}=1.25$

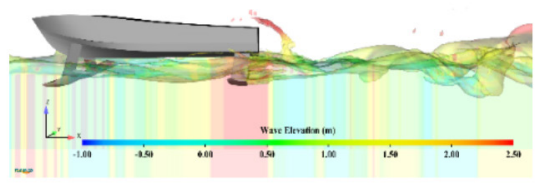

Figure 8: 2D view of wave elevation for various wavelengths 


\section{Conclusion}

The Computational Fluid Dynamics (CFD) simulation on predicting heaving and pitching motion of the hydrofoil was performed using Flow-3D software. The results showed that the increase of heaving and pitching motions led to the downgrade of her seakeeping performances presented in the form of high Response Amplitude Operator (RAO). The effects of the Froude Number in regular wave and foil angle of attack are as follows:

- The increase of the angle of the foil bow was proportional to the heave motion while for the foil stern at showed lower heave motion then followed by $5^{\circ}$ and $10^{\circ}$.

- While for pitch motion, the increase of the foil bow was lower at $5^{\circ}$ then followed by $10^{\circ}$ and $7.5^{\circ}$. The increase of the foil stern was proportional to the pitch motion experiences by hydrofoil.

- The heaving and pitching motions are much lower at $\lambda / \mathrm{Lpp}<1.25$. Further increment to $\lambda /$ Lpp 2 has led to higher heaving and pitching motions resulting in lower seakeeping performance.

Further investigation is required to have a better understanding in seakeeping behaviour of the hydrofoil ship.

\section{Acknowledgements}

Authors wished to thanked the university for the research opportunity and reviewers for the constructive comments.

\section{References}

Djavareshkian, M. H., \& Esmaeili, A. (2014). Heuristic optimization of submerged hydrofoil using ANFIS-PSO. Ocean Engineering, 92, 5563.

Fitriadhy, A., \& Adam, N. A. (2017). Heave and pitch motions performance of a monotricat ship in head-seas. International Journal of Automotive and Mechanical Engineering, 14, 4243-4258.

Islam, M., Jahra, F., \& Hiscock, S. (2016). Data analysis methodologies for hydrodynamic experiments in waves. Journal of Naval Architecture and Marine Engineering, 13(1), $1-15$.

Koutsourakis, N., Bartzis, J. G., \& Markatos, N. C. (2012). Evaluation of Reynolds stress, k- $\varepsilon$ and RNG k- $\varepsilon$ turbulence models in street canyon flows using various experimental datasets. Environmental fluid mechanics, 1-25.

Manual, F. D. U. (2011). Flow3D User Manual, v9. 4.2, Flow Science. Inc., Santa Fe, NM.

Matveev, K., \& Duncan, R. (2005). Development of the tool for predicting hydrofoil system performance and simulating motion of hydrofoil-assisted boats. Paper presented at the High Speed and High Performance Ship and Craft Symposium, Everett/WA: ASNE, USA.

Seif, M., Mehdigholi, H., \& Najafi, A. (2014). Experimental and numerical modeling of the high speed planing vessel motion. Journal of Marine Engineering \& Technology, 13(2), 6272.

Sun, X., Yao, C., Xiong, Y., \& Ye, Q. (2017). Numerical and experimental study on seakeeping performance of a swath vehicle in head waves. Applied Ocean Research, 68, 262275.

Vakilabadi, K. A., Khedmati, M. R., \& Seif, M. S. (2014). Experimental study on heave and pitch motion characteristics of a wave-piercing trimaran. Transactions of FAMENA, 38(3), 1326.

Yakhot, A., Rakib, S., \& Flannery, W. (1994). LowReynolds number approximation for turbulent eddy viscosity. Journal of scientific computing, 9(3), 283-292.

Yakhot, V., \& Orszag, S. A. (1986). Renormalization group analysis of turbulence. I. Basic theory. Journal of scientific computing, 1(1), 3-51. 
